Susanne Andrea Gujer-Bertschinger

Philipp von Huttens Tod in der Neuen Welt 
meiner Familie

Susanne Andrea Gujer-Bertschinger, geb. 1970, lehrt an der Pädagogischen Hochschule Zürich (PHZH) Deutsch-Didaktik sowie Forschung und Entwicklung und forscht $\mathrm{zu}$ postkolonialen Studien und Migration in Lateinamerika. 
Susanne Andrea Gujer-Bertschinger

\section{Philipp von Huttens Tod in der Neuen Welt}

Ein Kriminalfall, der das koloniale Schreiben in Gang setzte 
Dieses Buch ist die nur unwesentlich überarbeitete Fassung meiner Dissertation, die ich unter dem Titel »Philipp von Huttens Tod im kolonialen Archiv. Koloniales Schreiben, Subjektgefüge und bürokratischer Apparat im 16. Jahrhundert« im Juni 2018 am Romanischen Seminar der Universität Zürich verteidigt habe.

Publiziert mit Unterstützung des Schweizerischen Nationalfonds (SNF) zur Förderung wissenschaftlicher Forschung.

\section{NF}

Swiss national Science foundation

\section{Bibliografische Information der Deutschen Nationalbibliothek}

Die Deutsche Nationalbibliothek verzeichnet diese Publikation in der Deutschen Nationalbibliografie; detaillierte bibliografische Daten sind im Internet über http://dnb.d-nb.de abrufbar.

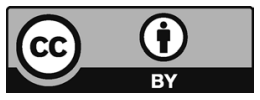

Dieses Werk ist lizenziert unter der Creative Commons Attribution 4.0 Lizenz (BY). Diese Lizenz erlaubt unter Voraussetzung der Namensnennung des Urhebers die Bearbeitung, Vervielfältigung und Verbreitung des Materials in jedem Format oder Medium für beliebige Zwecke, auch kommerziell. (Lizenztext:

https://creativecommons.org/licenses/by/4.o/deed.de)

Die Bedingungen der Creative-Commons-Lizenz gelten nur für Originalmaterial. Die Wiederverwendung von Material aus anderen Quellen (gekennzeichnet mit Quellenangabe) wie z.B. Schaubilder, Abbildungen, Fotos und Textauszüge erfordert ggf. weitere Nutzungsgenehmigungen durch den jeweiligen Rechteinhaber.

\section{Erschienen 2021 im transcript Verlag, Bielefeld (๖) Susanne Andrea Gujer-Bertschinger}

Umschlaggestaltung: Maria Arndt, Bielefeld

Umschlagabbildung: Manuskript der Zeugenaussagen des Juan Ruiz de Vallejo, Magdalena und Perico: Ministerio de Cultura y Deporte. Archivo General de Indias. Justicia, Leg. 992, No 4, 3a, 17vo-20vo.

Lektorat: Jan Wenke

Druck: Majuskel Medienproduktion GmbH, Wetzlar

Print-ISBN 978-3-8376-5448-6

PDF-ISBN 978-3-8394-5448-0

https://doi.org/10.14361/9783839454480

Gedruckt auf alterungsbeständigem Papier mit chlorfrei gebleichtem Zellstoff. Besuchen Sie uns im Internet: https://www.transcript-verlag.de Unsere aktuelle Vorschau finden Sie unter www.transcript-verlag.de/vorschau-download 